\title{
FITOTECNIA
}

\section{EMPREGO DA PODA VERDE PARA A OBTENÇÃO DE DUAS SAFRAS POR CICLO VEGETATIVO EM 'NIAGARA BRANCA’ (1)}

\author{
PAULO VITOR DUTRA DE SOUZA $\left({ }^{2 *}\right)$; MÁRIO LUÍS FOCHESATO $\left({ }^{3}\right)$
}

\begin{abstract}
RESUMO
Avaliou-se o efeito de épocas de poda verde em dois anos consecutivos visando obter a segunda safra de uva em um mesmo ciclo vegetativo na cv. Niágara Branca (Vitis labrusca L.), cultivada no sistema em espaldeira. O experimento foi realizado na Estação Experimental Agronômica da UFRGS, em Eldorado do Sul (RS), nas safras de 2003/2004 e 2004/2005. Os tratamentos constaram de três épocas de poda verde, realizadas imediatamente após a quarta folha acima do último cacho, e dois anos consecutivos de avaliação. Todas as plantas foram submetidas à superação de dormência mediante aplicação de cianamida hidrogenada a $2 \%$. Analisou-se a duração dos estádios fenológicos, o período de maturação, a produção por planta, a massa fresca do cacho, o teor de sólidos solúveis totais e a acidez total titulável. Observouse que a época de realização da poda verde não afetou a quantidade, nem a qualidade da uva produzida na primeira colheita, apenas atrasando-a em uma semana. A poda verde realizada no início de novembro possibilitou a segunda colheita de uva, realizada entre março e abril, sendo uma alternativa de ampliação do período de oferta do produto no mercado.
\end{abstract}

Palavras-chave: manejo da poda, Vitis labrusca, fenologia, produção.

\section{ABSTRACT \\ GREEN PRUNING TO OBTAIN TWO HARVESTS BY VEGETATIVE CICLE ON NIAGARA GRAPEVINE}

The aim of this study was to evaluate the effects of green prunings on two consecutive years to obtain a second harvest of 'Niagara Branca' (Vitis labrusca) grapevine in the same season. The experiment was carried out at Estação Experimental Agronômica of Universidade Federal do Rio Grande do Sul, located at Eldorado do Sul, State of Rio Grande do Sul, Brazil in 2003/ 2004 and 2004/2005 growth seasons. The grapevines were conducted by cordon training. The treatments involved three dates of green pruning, performed at fourth leaf situated above the last grape, and two seasons. All the plants were sprayed with hidrogenate cianamide $(2 \%)$ to overcome dormency. Fenology, plant production, weight of grapes, ${ }^{\circ}$ Brix and titratable acid were evaluated. The green pruning time season did not affect the Niagara production and quality of grapes in the first harvest, only delaying it by one week. The green pruning performed at the beginning of November provided a second harvest, between March and April, that is an alternative to offer grapes out of season.

Key words: prunning management, Vitis labrusca, pheenology, plant production.

$\left({ }^{1}\right)$ Recebido para publicação em 17 de maio de 2006 e aceito em 13 de abril de 2007.

$\left({ }^{2}\right)$ Departamento de Horticultura e Silvicultura, Faculdade de Agronomia, UFRGS, Av. Bento Gonçalves, 7712, Caixa Postal 15.100, 91501-970 Porto Alegre (RS). Email: pvdsouza@ufrgs.br. $\left({ }^{*}\right)$ Autor correspondente. Bolsista CNPq.

$\left({ }^{3}\right)$ Programa de Pós-Graduação em Fitotecnia, UFRGS. Email: mariofochesato@ig.com.br 


\section{INTRODUÇÃO}

A cultivar Niágara Branca (Vitis labrusca L.) é resultante do cruzamento entre Concord e Cassady, ocorrida em 1868, no condado de Niagara, Nova York, EUA (CAMAGRo, 1994). É bastante empregada como uva de mesa no Sul do Brasil (GiovanninI, 1999).

Na região tradicional de viticultura do Rio Grande do Sul (Encosta Superior do Nordeste), o pico de colheita da 'Niágara Branca' está situado entre a segunda quinzena de janeiro e a segunda quinzena de fevereiro, o que provoca uma queda nos preços como conseqüência da elevada oferta. A possibilidade de ampliação do período de colheita e comercialização de uvas de mesa, através de colheitas antecipadas ou tardias, permite maior ganho ao viticultor.

Conforme Kunn e Maia (2001) e Souza (1996) o cultivo de videiras em áreas tropicais possibilita a obtenção de duas ou mais safras por ano. Em regiões de clima temperado, como o Rio Grande do Sul e Santa Catarina, a videira produz somente uma colheita ao ano, pois entra em dormência no outono/ inverno. Entretanto, há regiões geográficas como a Depressão Central do Rio Grande do Sul, onde o inverno é mais ameno, sem ocorrência de geadas tardias, o emprego de algumas práticas culturais, como manejo das podas de inverno e verão, tem possibilitado a obtenção de colheitas em épocas diferenciadas, com duas colheitas por safra, permitindo maior preço de mercado pago ao viticultor (Fochesato e Souza, 2004). Esse processo é possível, graças à alteração da fenologia das plantas (SCHIEDECK, 1996; Fochesato e Souza, 2004; Souza et al., 2001).

O objetivo deste trabalho foi avaliar o comportamento da cultivar Niágara Branca submetida à diferentes épocas de poda verde, visando à obtenção de uma segunda colheita no mesmo ciclo vegetativo.

\section{MATERIAL E MÉTODOS}

O experimento foi desenvolvido na Estação Experimental Agronômica da UFRGS, em Eldorado do Sul, RS. O solo do local é classificado como Argissolo Vermelho Distrófico, de textura argilosa e relevo ondulado, tendo como substrato o granito. Segundo Köeppen, o clima da região é classificado como Cfa - subtropical úmido com verão quente e com pouca deficiência hídrica, com temperatura média do mês mais quente superior a $22{ }^{\circ} \mathrm{C}$ e a temperatura média do mês mais frio entre 3 e $18^{\circ} \mathrm{C}$. A precipitação pluvial anual média é de $1.445,8 \mathrm{~mm}$ e a umidade relativa do ar anual média é $77 \%$. A radiação solar global média é de $12,39 \mathrm{MJ} . \mathrm{m}^{-2}$. dia

1 (Bergamaschi et al., 2004).

O vinhedo utilizado (com 12 anos de idade) foi com a cultivar Niágara Branca (Vitis labrusca L.), enxertada sobre o porta-enxerto 101-14 mgt, com espaçamento de $1,20 \times 3,00 \mathrm{~m}$ e conduzido em espaldeira, com três fios de arame. Na poda de inverno, deixou-se 2 a 3 gemas por esporão, sendo mantidas aproximadamente 20 gemas por planta.

Desenvolveu-se o trabalho em dois ciclos vegetativos, compreendendo duas safras, testando-se três épocas de poda verde:

Na safra de 2004, as podas verdes foram realizadas nas seguintes datas: $1 .^{a}$ época $(14 / 11 /$ 2003), 2. ${ }^{a}$ época $(28 / 11 / 2003)$ e $3 .^{a}$ época $(10 / 12 /$ 2003), ou seja, executadas aos 98,112 e 124 dias após a poda de inverno, realizada em 8 de agosto de 2003.

$\mathrm{Na}$ safra de 2005 as épocas de poda verde foram: 1 . $^{a}$ época $(8 / 11 / 2004), 2$. $^{a}$ época $(24 / 11 / 2004)$ e 3 . $^{\text {a época }}(9 / 12 / 2004)$, ou seja, executadas aos 109 , 125 e 140 dias após a poda de inverno, realizada em 22 de julho de 2004).

Após a execução da poda de inverno aplicouse cianamida hidrogenada a $2 \%$ em todas as plantas.

A poda verde consistiu no corte do sarmento do ano após a $4 .{ }^{\text {a }}$ folha acima do último cacho, visando à brotação da gema da base da última folha. As plantastestemunha receberam somente desponte do sarmento na altura acima do $3 .^{\circ}$ fio de arame, correspondendo a 8 a 10 folhas acima do último cacho.

No momento da poda verde os sarmentos estavam maduros (coloração marrom) e com diâmetro médio de $8 \mathrm{~mm}$ no local do corte. A quarta folha acima do último cacho estava plenamente desenvolvida.

O delineamento experimental utilizado foi de blocos casualizados, com duas plantas por parcela e quatro repetições.

Os tratamentos fitossanitários seguiram as recomendações técnicas para a cultura da videira (SÔNEGO et al., 2004).

Avaliou-se o ciclo fenológico das videiras, conforme classificação de BAGGIOLINI (1952), assim como o período de maturação da uva. Também foram avaliados a produção por planta $(\mathrm{kg})$, a massa fresca dos cachos (g), o teor total de sólidos solúveis (SST) e a acidez total titulável (ATT).

A produção por planta foi obtida pela média de pesagem dos cachos colhidos em balança analítica. Pela divisão da massa fresca de frutos por planta pelo número de cachos colhidos obteve-se a massa fresca média dos cachos. 
$\mathrm{O}$ valor de SST ( ${ }^{\circ}$ Brix) foi determinado em refratômetro de mesa, modelo 2 WAJ. A ATT (meq. $\mathrm{L}^{-1}$ ) foi determinada por titulação com $\mathrm{NaOH} 0,1 \mathrm{~N}$ e com um peagômetro DIGIMED, modelo DM-20, devidamente calibrado, determinando a quantidade de solução gasta até atingir o $\mathrm{pH} 8,1$. Dessa forma, utilizaram-se $10 \mathrm{~mL}$ de mosto, acrescidos de $90 \mathrm{~mL}$ de água destilada, sendo os valores obtidos pela fórmula: ATT $\left(\right.$ meq. $\left.\mathrm{L}^{-1}\right)=$ Volume de $\mathrm{NaOH}(\mathrm{ml}) \times 10$ (CATAluña, 1984). Para o SST e ATT, utilizaram-se cinco cachos de uva por unidade experimental.

As precipitações pluviais e as temperaturas médias mensais ocorridas durante o período de realização do experimento nas safras 2003/2004 e 2004/2005, e da Normal (1970-2000) (BERGAMASCHI et al., 2004) estão apresentadas na figura 1.

As médias dos tratamentos em cada safra e entre elas foram comparadas pelo teste de Tukey a 5\% de probabilidade.

\section{RESULTADOS E DISCUSSÃO}

O ciclo fenológico da 'Niágara Branca' foi maior em 2004/ 2005 comparativamente ao de 2003/ 2004, como conseqüência do maior período entre a poda e a floração (Tabela 1). Esse período foi maior no ano 2004/2005 em virtude de ter-se podado mais cedo $(22 / 7 / 04)$ em relação ao ano anterior $(8 / 8 / 03)$, corrrespondendo a uma diferença de 17 dias, coincidindo com um maior período de temperaturas baixas (Figura 1), atrasando a brotação e a floração das videiras. Apesar de ter apresentado um ciclo fenológico maior no ano de 2004/2005, a colheita destas plantas pôde ser iniciada uma semana antes em relação ao ano anterior, sendo a diferença das médias do ciclo fenológico (com e sem poda verde) entre os anos, de 11 dias.

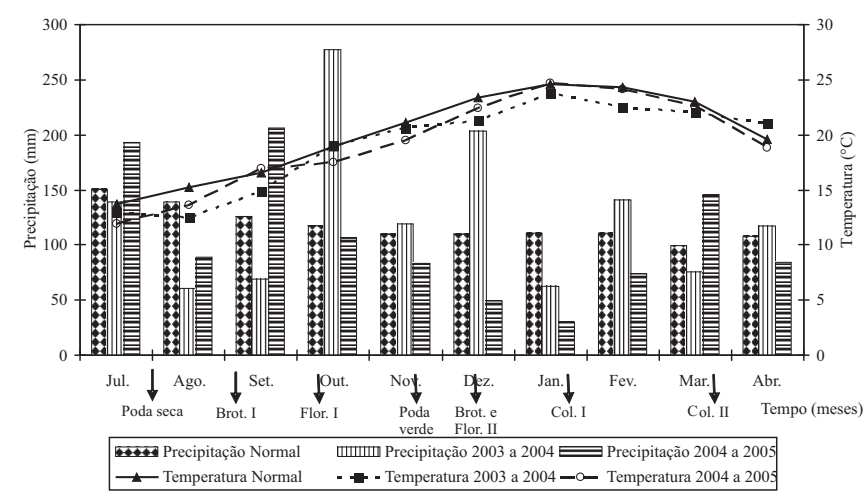

Figura 1. Precipitação e temperatura média mensal durante o período de execução do experimento (julho a abril) nas safras 2003/2004 e 2004/2005, e da Normal (19702000, Bergamaschi et al., 2004). EEA/ UFRGS. Eldorado do Sul. Nota: Brot.= Brotação, Flor. $=$ Floração e Col.= Colheita; $(I)=$ referente à primeira colheita da poda seca e $(\mathrm{II})=$ referente à segunda colheita da poda verde.
O estádio fenológico envolvendo o período da floração à colheita foi maior naquelas plantas submetidas à poda verde comparativamente àquelas somente despontadas na altura do terceiro fio de arame (Tabela 1). Este aumento no último estádio fenológico provavelmente se deve à alteração na translocação de fotoassimilados das folhas remanescentes. Desse modo, nas plantas não podadas os fotoassimilados seriam translocados principalmente aos frutos; enquanto que na presença da poda os fotoassimilados seriam deslocados para promover o desenvolvimento das novas brotações.

De acordo com Giovannini (1999), o ciclo da 'Niágara Branca' é de 151 dias na Encosta Superior do Nordeste do Rio Grande do Sul, considerando desde a brotação até a colheita, estando muito próximo das videiras não submetidas à poda verde, que foi de 152 dias, e daquelas podadas, cujo ciclo médio foi de 156 dias.

A produção por planta, a massa fresca do cacho, o teor de sólidos solúveis totais (SST) e a acidez total titulável (ATT) estão apresentados na tabela 2. Observa-se que para esses caracteres, a época de realização da poda verde não influiu significativamente. A produtividade e a qualidade das uvas das plantas somente despontadas na altura do terceiro fio de arame foram semelhantes às submetidas às diferentes épocas de poda verde.

Não houve influência do ano agrícola na produção por planta e nos sólidos solúveis totais . A massa fresca do cacho e a ATT diferiram significativamente entre os anos avaliados independentemente da época da poda verde (Tabela 2). Assim, a massa fresca do cacho foi maior na safra de 2004, quando comparada com massa fresca dos cachos colhidos em 2005. Mesmo assim, os cachos de ambas as safras foram considerados de primeira categoria por pesarem mais de $100 \mathrm{~g}$ (MANFROI et al., 1996). A menor massa fresca dos cachos na safra de 2005 deve-se, provavelmente, à baixa precipitação pluvial ocorrida durante o ciclo vegetativo (Figura 1), a qual foi muito inferior à Normal, e que em termos absolutos teria induzido também menor produção por planta. Na safra de 2005, a ATT foi 50,54 meq. - $^{-1}$ superior à safra de 2004, o que pode ser explicado pelo alto estresse hídrico ocorrido nesta última safra, supostamente dificultando a transformação dos ácidos orgânicos, mesmo com o aumento da temperatura, a qual foi potencializada ainda mais pela falta de água.

As plantas não submetidas à poda verde (somente despontadas na altura do terceiro fio de arame) praticamente não brotaram com o desponte; portanto, não houve a segunda colheita, o que foi observado naquelas podadas acima da quarta-folha (Tabelas 3 e 4 ). 
Tabela 1. Duração, em dias, dos estádios fenológicos e do período de maturação da primeira colheita na cultivar Niágara Branca, submetida ou não à poda verde. EEA/ UFRGS. Eldorado do Sul, médias das safras 2004 e 2005

\begin{tabular}{|c|c|c|c|c|c|c|c|c|c|c|c|c|}
\hline \multirow{4}{*}{$\begin{array}{l}\text { Poda } \\
\text { verde }\end{array}$} & \multicolumn{8}{|c|}{ Estádios fenológicos (dias) } & \multicolumn{4}{|c|}{ Período de maturação } \\
\hline & \multirow{2}{*}{\multicolumn{2}{|c|}{$\begin{array}{c}\mathrm{P} / \mathrm{B}\left({ }^{1}\right) \\
\text { Safra }\end{array}$}} & \multirow{2}{*}{\multicolumn{2}{|c|}{$\begin{array}{l}\text { B/F }\left({ }^{2}\right) \\
\text { Safra }\end{array}$}} & \multirow{2}{*}{\multicolumn{2}{|c|}{$\begin{array}{c}\mathrm{F} / \mathrm{C}\left({ }^{3}\right) \\
\text { Safra }\end{array}$}} & \multirow{2}{*}{\multicolumn{2}{|c|}{$\begin{array}{l}\text { Total } \\
\text { Safra }\end{array}$}} & \multirow{2}{*}{\multicolumn{2}{|c|}{$\begin{array}{l}\text { Início } \\
\text { Safra }\end{array}$}} & \multirow{2}{*}{\multicolumn{2}{|c|}{$\begin{array}{l}\text { Final } \\
\text { Safra }\end{array}$}} \\
\hline & & & & & & & & & & & & \\
\hline & 2004 & 2005 & 2004 & 2005 & 2004 & 2005 & 2004 & 2005 & 2004 & 2005 & 2004 & 2005 \\
\hline Com & 26 & 32 & 31 & 37 & 122 & 123 & 179 & 192 & $2 / 01$ & $23 / 12$ & $2 / 02$ & $28 / 01$ \\
\hline Sem & 26 & 32 & 31 & 37 & 119 & 116 & 176 & 185 & $27 / 12$ & $21 / 12$ & $30 / 01$ & $21 / 01$ \\
\hline
\end{tabular}

$\left({ }^{1}\right) \mathrm{P} / \mathrm{B}=$ Poda à brotação. $\left({ }^{2}\right) \mathrm{B} / \mathrm{F}=$ Brotação à floração. $\left({ }^{3}\right) \mathrm{F} / \mathrm{C}=$ Floração à colheita.

Tabela 2. Produção média por planta, massa fresca do cacho, sólidos solúveis totais (SST) e acidez total titulável (ATT) da primeira colheita em plantas de Niágara Branca, submetidas a três épocas de poda verde. EEA/ UFRGS. Eldorado do Sul, nas safras de 2004 e 2005

\begin{tabular}{|c|c|c|c|c|c|c|c|c|}
\hline \multirow{2}{*}{$\begin{array}{l}\text { Poda verde } \\
\text { Época }\end{array}$} & \multicolumn{2}{|c|}{ Produção } & \multicolumn{2}{|c|}{ Massa fresca } & \multicolumn{2}{|c|}{ SST } & \multicolumn{2}{|c|}{ ATT } \\
\hline & Safra 2004 & Safra 2005 & Safra 2004 & Safra 2005 & Safra 2004 & Safra 2005 & Safra 2004 & Safra 2005 \\
\hline & \multicolumn{2}{|c|}{$\mathrm{kg} \cdot \mathrm{planta}^{-1}$} & \multicolumn{2}{|c|}{-g.cacho ${ }^{-1}$} & \multicolumn{2}{|c|}{${ }^{\circ}$ Brix } & \multicolumn{2}{|c|}{$-\mathrm{meq} \cdot \mathrm{L}^{-1}$} \\
\hline 1 & 10,64 & 10,10 & 232,00 & 168,00 & 13,43 & 12,63 & 59,00 & 11268 \\
\hline 2 & 12,13 & 8,89 & 213,00 & 165,00 & 12,74 & 12,63 & 77,00 & 130,13 \\
\hline 3 & 13,64 & 10,33 & 216,00 & 164,00 & 12,62 & 12,89 & 66,56 & 111,40 \\
\hline Médias & 12,13 & 9,8 & $220 \mathrm{~A}$ & $166 \mathrm{~B}$ & 12,93 & 12,72 & $67,53 \mathrm{~B}$ & $118,07 \mathrm{~A}$ \\
\hline C.V. $(\%)$ & \multicolumn{2}{|c|}{32,0} & \multicolumn{2}{|c|}{38,5} & \multicolumn{2}{|c|}{8,6} & \multicolumn{2}{|c|}{18,0} \\
\hline
\end{tabular}

Médias seguidas por letra diferente, na linha, diferem significativamente pelo teste de Tukey, a 5\% de probabilidade.

Tabela 3. Duração, em dias, dos estádios fenológicos e do período de maturação da segunda colheita na cultivar Niágara Branca, submetida à poda verde. EEA/ UFRGS. Eldorado do Sul, médias das safras 2004 e 2005

\begin{tabular}{|c|c|c|c|c|c|c|c|c|c|c|c|c|}
\hline \multirow{3}{*}{$\begin{array}{l}\text { Poda } \\
\text { verde }\end{array}$} & \multicolumn{8}{|c|}{ Estádios fenológicos (dias) } & \multicolumn{4}{|c|}{ Período de maturação } \\
\hline & \multicolumn{2}{|c|}{$\mathrm{P} / \mathrm{B}^{(1)}$} & \multicolumn{2}{|c|}{$\mathrm{B} / \mathrm{F}^{(2)}$} & \multicolumn{2}{|c|}{$\mathrm{F} / \mathrm{C}^{(3)}$} & \multicolumn{2}{|c|}{ Total } & \multicolumn{2}{|c|}{ Início } & \multicolumn{2}{|c|}{ Final } \\
\hline & & & & & & & & & & & & fra \\
\hline Ероса & 2004 & 2005 & 2004 & 2005 & 2004 & 2005 & 2004 & 2005 & 2004 & 2005 & 2004 & 2005 \\
\hline 1 & 19 & 24 & 13 & 17 & 89 & 91 & 121 & 132 & $01 / 03$ & $03 / 03$ & $13 / 03$ & $18 / 03$ \\
\hline 2 & 14 & 18 & 19 & 25 & 83 & 82 & 116 & 125 & $07 / 03$ & $12 / 03$ & $21 / 03$ & $29 / 03$ \\
\hline 3 & 17 & 19 & 23 & 25 & 83 & 77 & 123 & 121 & $28 / 03$ & $24 / 03$ & $12 / 04$ & $08 / 04$ \\
\hline
\end{tabular}

$\left({ }^{1}\right) \mathrm{P} / \mathrm{B}=$ Poda à brotação. $\left({ }^{2}\right) \mathrm{B} / \mathrm{F}=$ Brotação à floração. $\left({ }^{3}\right) \mathrm{F} / \mathrm{C}=$ Floração à colheita.

Tabela 4. Produção por planta, massa fresca do cacho, sólidos solúveis totais (SST) e acidez total titulável (ATT) da segunda colheita em plantas de Niágara Branca, submetidas a três épocas de poda verde. EEA/ UFRGS. Eldorado do Sul, nas safras de 2004 e 2005

\begin{tabular}{|c|c|c|c|c|c|c|c|c|}
\hline \multirow{2}{*}{$\begin{array}{l}\text { Poda verde } \\
\text { Época }\end{array}$} & \multicolumn{2}{|c|}{ Produção } & \multicolumn{2}{|c|}{ Massa fresca } & \multicolumn{2}{|c|}{ SST } & \multicolumn{2}{|c|}{ ATT } \\
\hline & Safra 2004 & Safra 2005 & Safra 2004 & Safra 2005 & Safra 2004 & Safra 2005 & Safra 2004 & Safra 2005 \\
\hline & \multicolumn{2}{|c|}{-kg.planta ${ }^{-1}$} & \multicolumn{2}{|c|}{ g.cacho ${ }^{-1}$} & \multicolumn{2}{|c|}{${ }^{\circ}$ Brix } & \multicolumn{2}{|c|}{ meq. $\mathrm{L}^{-1}$} \\
\hline 1 & 3,63 Аa & 0,70 Ba & $115 \mathrm{Aa}$ & $112 \mathrm{Aa}$ & 16,81 & 16,00 & 102,19 & 107,93 \\
\hline 2 & $0,54 \mathrm{Ab}$ & 0,09 Aa & $90 \mathrm{Aa}$ & $70 \mathrm{Ab}$ & - & - & - & - \\
\hline 3 & $0,13 \mathrm{Ab}$ & $0,00 \mathrm{Aa}$ & $90 \mathrm{Aa}$ & $00 \mathrm{Bc}$ & - & - & - & - \\
\hline C.V. $(\%)$ & \multicolumn{2}{|c|}{36,0} & \multicolumn{2}{|c|}{39,0} & & & & \\
\hline
\end{tabular}

Médias seguidas pela mesma letra, minúsculas na coluna e maiúsculas na linha, não diferem significativamente pelo teste de Tukey, a $5 \%$ de probabilidade. 
O acompanhamento dos estádios fenológicos e do período de maturação referente às três épocas de realização da poda verde visando a obtenção de uma segunda colheita, está representada na tabela 3. De maneira geral, nos estádios fenológicos envolvendo da poda à brotação e da floração à colheita observou-se comportamento decrescente à medida que se atrasou a poda verde, provavelmente como conseqüência do aumento da temperatura média da primavera para o verão (Figura 1). No entanto, no estádio de brotação à floração notou-se comportamento inverso, devido ao estresse hídrico ocorrido no fim de dezembro até o início de fevereiro, retardando o ciclo de desenvolvimento da planta. No total, o estádio fenológico médio entre anos da 'Niágara Branca' variou de 121 a 127 dias nesta segunda brotação com a realização da poda verde. Também CONTE (1998), trabalhando com 'Niágara Rosada', no sistema latada, obteve um valor intermediário de 126 dias com a execução da poda verde.

O período de maturação da segunda safra, observado na tabela 3, com a colheita ocorrendo entre março e abril, permite um escalonamento da produção nos meses em que há pouca oferta de uva no mercado, possibilitando maior valorização do produto ao viticultor.

Na tabela 4, estão indicadas as médias de produtividade e a qualidade da uva na segunda colheita. A produção por planta e a massa fresca dos cachos foram sujeitas à interação entre a época de poda verde e as safras avaliadas. A primeira época de poda verde induziu estatisticamente maior produtividade, na safra de 2004, e a terceira época de poda verde, maior massa fresca do cacho nessa safra. Houve diferenças entre épocas para a produtividade, na safra de 2004, e para a massa fresca, na safra de 2005. O pior desempenho da segunda e terceira épocas de poda verde deve-se às baixas precipitações pluviais ocorridas. Na safra de 2005 (Figura 1) todas as épocas foram afetadas, reduzindo a brotação e dificultando a floração dos cachos, que induziu um estado de pré-dormência às plantas pelo estresse hídrico, o que poderia ser contornado com o manejo da irrigação. À semelhança desse experimento, SCHIEDECK (1996) também verificou baixa brotação das gemas em 'Niágara Rosada' como causa da deficiência hídrica do solo.

A produção por planta e a massa fresca do cacho obtidos na primeira época de poda verde nas duas safras foram superiores às encontradas por CONTE (1998), que trabalhando com 'Niágara Rosada' no sistema de latada, obteve $498 \mathrm{~g}$ por planta e $98,5 \mathrm{~g}$ de massa fresca por cacho. Além disso, os cachos colhidos nas plantas submetidas à primeira época de poda verde são considerados de primeira categoria por pesarem mais de $100 \mathrm{~g}$ ( MANFrOI et al., 1996).
Pela escassa produção obtida na segunda e terceira épocas de poda verde, somente foi possível analisar o SST e a ATT com as uvas da primeira época de poda verde (Tabela 4). Não houve diferença de SST e ATT entre as safras avaliadas. O teor de açúcar dessa segunda colheita foi superior ao da primeira colheita, provavelmente como conseqüência das melhores condições climáticas, ficando acima do indicado por Mello e MaIA (2001), entre 14 e $16^{\circ}$ Brix, para uvas de mesa. Observou-se um aumento médio de 35 meq. $\mathrm{L}^{-1}$ no valor de ATT, na segunda colheita de 2004, quando comparado ao da primeira colheita. Esse processo ocorreu, provavelmente, devido à menor degradação dos ácidos orgânicos, pela redução da temperatura e pelo alto estresse hídrico ocorrido nesse período (Figura 1). Por outro lado, na safra de 2005 houve menor redução $\left(10,14\right.$ meq. $\left.\mathrm{L}^{-1}\right)$, valores muito próximos, pois nesta safra a precipitação pluvial foi muito inferior à ocorrida na safra anterior, afetando a degradação dos ácidos. De acordo com CONTE (1998), a degradação dos ácidos verificados no mosto da uva é dificultada em baixas temperaturas e em períodos de baixa precipitação pluvial, como conseqüência da menor absorção de cátions do solo.

\section{CONCLUSÕES}

1. A época de realização da poda verde não afeta a quantidade e a qualidade da uva da cv. Niágara Branca na primeira colheita.

2. A poda verde realizada no início de novembro possibilita uma segunda colheita em Niágara Branca, significando um ganho extra ao viticultor.

\section{REFERÊNCIAS}

BAGGIOLINI, M. Lês stades repès dans le dèveloppement annuel de la vigne et leur utilisation pratique. Revue Romande d'Agriculture et d'Arboriculture, v.8, n.1, p. 4-6, 1952.

BERGAMASCHI, H.; GUADAGNIN, M.R.; CARDOSO, L.S.; SILVA, M.I.G. Clima da Estação Experimental da UFRGS (e região de abrangência). Porto Alegre: UFRGS, 78p., 2004.

CAMARGO, U.A. Uvas do Brasil. Brasília: EMBRAPA-SPI, 1994, 90p. (Embrapa-CNPUV. Documentos, 9)

CATALUÑA, E. Uvas e vinhos. Rio de Janeiro: Globo, 230p. 1984.

CONTE, A. Comportamento da videira Niágara Rosada submetida à poda de verão, sob estufa plástica em Bento Gonçalves, RS: síntese da dissertação de Mestrado. Porto Alegre: EMATER/RS, 1998. 35p. 
FOCHESATO, M; SOUZA, P.V.D. Épocas de poda verde para a obtenção de duas safras por ciclo vegetativo na Depressão Central do Rio Grande do Sul. In.: CONGRESSO BRASILEIRO DE FRUTICULTURA, 18., 2004, Florianópolis. Resumos... Florianópolis: EPAGRI, 2004, v. 1, n. 1. CD-ROM.

GIOVANNINI, E. Produção de uvas para vinho, suco e mesa. Porto Alegre: Renascença, 364 p., 1999.

KUHN, G.B.; MAIA, J.D.G. Cultivo da Niágara Rosada em áreas tropicais do Brasil. Bento Gonçalves, RS: Embrapa Uva e Vinho, 2001. 72p.

MANFROI, V.; MARODIN, G.A.B.; SEIBERT, E.; ILHA, L.L.H.; MOLINOS, P.R. Quebra de dormência e antecipação da colheita em videira cv. Niágara Rosada. Revista Brasileira de Fruticultura, Cruz das Almas, v.18, n.1, p.65-74, 1996.

MELLO, L.M.R.; MAIA, J.D.G. Rentabilidade e Exigências de Mercado. In: KUHN, G.B.; MAIA, J.D.G. Cultivo da Niágara Rosada em áreas tropicais do Brasil. Bento Gonçalves, RS: Embrapa Uva e Vinho, p. 64-70, 2001.
SCHIEDECK, G. Ecofisiologia da videira e qualidade de uma Niágara Rosada conduzida sob estufa de plástico, 1996. 111f. Dissertação (Mestrado em Fitotecnia)-Faculdade de Agronomia-Universidade Federal do Rio Grande do Sul, Porto Alegre, 1996.

SÔNEGO, O.R. BOTTON, M.; MAIA, J.D.G.; GARRIDO, L.R. Doenças e Pragas. In: MAIA, J.D.G.; KUHN, G.B. Cultivo da Niágara Rosada em áreas tropicais do Brasil. Bento Gonçalves, RS: Embrapa Uva e Vinho, p. 1-77, 2004.

SOUSA, J.S.I. Uvas para o Brasil. Piracicaba: Fundação de Estudos Agrários Luiz de Queiroz - FEALQ, 1996. 791p.

SOUZA, P.V.D., BÜTTENBENDER, D.; AGOSTINI, S. Influência de épocas de poda verde e quebra de dormência sobre a fenologia e prudução da cultivar Niágara rosada na Depressão Central do Rio Grande do Sul. In.: Congresso Latinoamericano de Viticultura e Enologia, 8, 2001, Montevidéu, Resumos... Montevidéu: INAVI, v.1, n.1. CD-ROM. 